\title{
Heat Transfer Analysis and Modification of Thermal Probe for Gas-Solid Measurement
}

\author{
Hong Zhang and Xiangying Qi \\ National Key Laboratory of Science and Technology on Multispectral Information Processing, School of Automation, \\ Huazhong University of Science and Technology, Wuhan 43004, China \\ Correspondence should be addressed to Hong Zhang; sunracer@mail.hust.edu.cn
}

Received 22 November 2015; Accepted 5 January 2016

Academic Editor: Yuan Fan

Copyright (C) 2016 H. Zhang and X. Qi. This is an open access article distributed under the Creative Commons Attribution License, which permits unrestricted use, distribution, and reproduction in any medium, provided the original work is properly cited.

\begin{abstract}
The presented work aims to measure the gas-solid two-phase mass flow-rate in pneumatic conveyor, and a novel modified thermal probe is applied. A new analysis of the local heat transfer coefficients of thermal probe is presented, while traditional investigations focus on global coefficients. Thermal simulations are performed in Fluent 6.2 and temperature distributions of the probe are presented. The results indicate that the probe has obviously stable and unstable heat transfer areas. Based on understanding of probe characteristics, a modified probe structure is designed, which makes the probe output signal more stable and widens the measuring range. The experiments are carried out in a special designed laboratory scale pneumatic conveyor, and the modified probe shows an unambiguous improvement of the performance compared with the traditional one.
\end{abstract}

\section{Introduction}

It is usual that the solid powder is transported in industrial plant by pneumatic conveyor. The particularly important examples are the transport of granular and pulverized coal for boiler and blast furnace. In those processes, on-line measurement of mass flow-rate in gas-solid two-phase flow is a common problem that has never been solved successfully [1].

Lots of methods were used to solve this problem, including static electricity, microwave, tomography, and pressure drop. Nowadays, the thermal method is also applied to the gas-solid measurement. As a long time used sensor which measures gas mass flow in industry, the thermal probe is extended to measure the gas-solid two-phase flow. The first use of thermal probe to measure gas-solid flow should be owed to Moriyama et al. [2] since 1985. The authors developed a noninvasive differential temperature sensing method for the mass flow rate $0-1,000 \mathrm{~kg} / \mathrm{h}$ and mass flow ratio $0-47.2 \mathrm{~kg} / \mathrm{kg}$. The researchers including Zheng et al. [3, 4], Liu et al. [5], Yuan and $\mathrm{Lu}$ [6], and Zhang and $\mathrm{Li}$ [7] have focused on this area recently.

Our previous works include investigations on traditional heat balance method, thermal probe method $[7,8]$, and data fusion to achieve better performance [9]. By applying the thermal probe theory to measure the mass flow-rate of gassolid two-phase flow, the variety of solids loads in pneumatic conveying system, but two shortages are observed including signal fluctuation and severe on-linearity causing narrow measurement range.

Commonly, the thermal probe has fast response time and high sensitivity and the issues of worse zero stability and signal fluctuation. To apply the thermal probe to detect the gas-solid flow, the heat transfer characteristics research in detail is needed to solve the problems of stability and range extension. Theoretical analysis and numerical simulation help us to study and find new solution to improve the probe performance in gas-solid.

While the details of heat transfer behavior in gas-solid flow are not yet well understood, the early experimental results have already supported the thermal probe's application in solids mass flow-rate measurement [10-12]. Experimental investigations have proved that the wall Nusselt number is a function of the solid mass loading ratio. The Nusselt number will significantly increase in higher solids loading ratios because the heat transfer is enhanced caused by gas boundary layer influence due to solids. By using a four-way coupling Eulerian-Lagrangian model to simulate nonisothermal 
gas-solid flow in a vertical pipe, El-Behery et al. pointed out that the presence of solid particles reduces the boundary layer thickness and this reduction increases as the mass loading ratio increases [13]. With the recent improvement of the related mathematical models, the computational fluid dynamics (CFD) tools are strong enough to describe the heat transfer and dynamics behavior of gas-solid two-phase flow. The commercial software such as Fluent has been validated in many situations [14]. Fluent 6.2 was chosen as a simulation tool in analyzing the heat transfer of the thermal probe in the presented work.

\section{Analysis of Heat Transfer Equation of Thermal Probe in Single-Phase Flow}

For a thin heated cylinder placed in fluid (namely, hot wire), the way of heat transfer between cylinder and fluid is mainly performed as forced convection. King concluded an empirical formula of convective heat transfer between "infinite" cylinder and fluid through experimental and theoretical studies in 1914:

$$
\mathrm{Nu}=A+B \mathrm{Re}^{1 / 2}
$$

In (1), $A$ and $B$ are constant. With regard to the specific fluid within identified temperature and pressure, fluid density $\rho$, cylinder diameter $d$, and fluid viscosity $\mu$ can be regarded as constant and integrated into $A$ and $B$. According to the definition of Nusselt number and the relationship between Nusselt number $\mathrm{Nu}$ and fluid flow $U$ of convective heat transfer, heat transfer coefficient of cylinder $h$ can be obtained as

$$
h=\frac{k}{d}\left(A+B U^{1 / n}\right),
$$

where $k$ is the fluid heat conductivity and $d$ is the cylinder diameter.

While the hot wire conducts convective heat transfer with fluid, it is heated by an external electrical source. Then the hot wire heat transfer equation derived by King's equations can be expressed as

$$
\frac{I^{2} R_{w}}{R_{w}-R_{f}}=A+B U^{1 / 2},
$$

where $R_{w}$ is the resistance of hot wire when it is at a certain temperature $T_{w}$ and $R_{f}$ is the resistance of hot wire when it is at fluid temperature. The resistances of hot wire $R_{w}$ and $R_{f}$ are functions of temperature, and $I^{2} R_{w}$ is heating power in the thermal equilibrium state; moreover, $\left(R_{w}-R_{f}\right)$ has a linear relationship with the temperature difference and is characterized as the temperature difference between hot wire and fluid. $A$ and $B$ can be determined by calibration.

Considering that (1) is based on an infinite hot wire, the rate of length and diameter of hot wire is large enough (the rate of length and diameter of typical hot wire is more than 300 , which are, resp., $1.25 \mathrm{~mm}$ and $4 \mu \mathrm{m}$ ). If cylinder length/diameter rate is taken into account, the index $n$ on velocity $U$, which is available for calibration, should be changed. Therefore, for the cylinder with finite-length, (3) can be rewritten as

$$
\frac{I^{2} R_{w}}{R_{w}-R_{f}}=A+B U^{n} .
$$

Notably, $A$ and $B$ here contain fluid parameters such as fluid density, viscosity, thermal conductivity, and specific heat, and they are assumed to be constant during the measurement. However, these parameters may vary along with the state of temperature, fluid component, and so on. The related investigations belong to temperature and components compensation of thermal probe and are not discussed in this paper.

2.1. Fluid Density Is Not a Constant. As the range of temperature and pressure is rather large, fluid density is bound to fluctuate. The following heat transfer equation of thermal probe reveals that heat transfer of thermal probe is related with local mass flow of fluid $q_{M}$, so the fluid density can be expressed in the output of thermal probe and then thermal probe can be used to directly measure the mass flow of fluid:

$$
\frac{I^{2} R_{w}}{R_{w}-R_{f}}=A+B\left(q_{M}\right)^{n} .
$$

This equation is called heat transfer equations of thermal mass flow meter. In other words, the local mass flow flowing around thermal probe has a determined nonlinear relationship with temperature of speed probe (which is characterized by $R_{w}$ ), temperature of fluid (which is characterized by $R_{f}$ ), and the heating current. The local mass flow of thermal probe can be obtained when the heat transfer probe works in constant power mode or constant temperature differential mode.

2.2. Prandtl Number Is Not a Constant. At high Reynolds number, Prandtl number should not simply be seen as a constant in more general equations of fluid heat transfer because there was a certain degree of error in (1). Researches at home and abroad on heat transfer criteria equation $\mathrm{Nu}=$ $f(\mathrm{Re}, \mathrm{Pr})$ of flowing around cylinder show that a more precise heat transfer expression is needed in a larger measurement range.

In different flow states, different heat transfer criteria equations can be used to analyze coefficients $A$ and $B$. Here, criteria equation obtained from Kramers experiment is adopted and can be described as

$$
\mathrm{Nu}=0.42 \operatorname{Pr}^{0.2}+0.57 \operatorname{Pr}^{0.33} \operatorname{Re}^{0.50} .
$$

It is appropriate at $0.01<\operatorname{Re}<10000$ and $0.71<\operatorname{Pr}<$ 1000 range.

Meanwhile, constants $A$ and $B$ in (4) should be

$$
\begin{aligned}
& A=0.42 \frac{\pi k l}{\alpha_{0} R_{0}}\left(\frac{c_{p} \mu}{k}\right)^{0.2}, \\
& B=0.57 \frac{\pi k l}{\alpha_{0} R_{0}}\left(\frac{c_{p} \mu}{k}\right)^{0.33}\left(\frac{d}{\mu}\right)^{n} .
\end{aligned}
$$


Among them, the temperature coefficient $\alpha_{0}$ of heating resistance, the resistance $R_{0}$ at the reference temperature, the length $l$ of heat cylinder, and the diameter $d$ are inherent constants of the probe; the thermal conductivity $k$ of fluid, the specific heat capacity $c_{p}$, and the dynamic viscosity $\mu$ are related to the temperature. When determining the specific values of these parameters, the film temperature is applied, which is defined as the average values of the temperature of probe and the temperature of fluid; namely,

$$
T_{\text {film }}=\frac{\left(T_{w}-T_{f}\right)}{2} .
$$

Leaving aside the small differences of specific coefficients in expressions of $A$ and $B$, due to utilizing different heat transfer criteria equations, equations could be used to qualitatively analyze and research calibration constants for thermal mass flow probe.

The heat transfer criteria equations listed above are empirical relationship obtained by considering the overall heat transfer coefficient of the probe. Actually, the distribution of the local heat transfer coefficient has a big difference. The next section will specifically discuss the local heat transfer coefficient of the probe to help to improve the design of the probe in the later chapters.

\section{Analysis of Local Heat Transfer Coefficient of Thermal Probe}

It can be seen from the whole heat transfer theory described above that the thermal probe measures the velocity of flow and mass flow was actually achieved by measuring the heat transfer characteristics of the thermal probe. So it is necessary to further study the local heat transfer coefficient of thermal probe. The heat transfer coefficient is closely related to the fluid mechanics behavior while fluid flows around the thermal probe.

3.1. Analysis of Flow Patterns While Fluid Flows around the Probe. When the fluid passes along a perpendicular direction to the axis of the cylinder, the fluid has characteristics with boundary layer. The fluid flowing across the probe may cause emerging inverse flow, whirlpool, and vortex beam. When the Reynolds number is very low, the boundary layer separation does not occur and the fluid flowing around cylinder appears as a status of climb stream. With the increase of the Reynolds number, a certain frequency of vortex will be started up.

The angle $\varphi$ starting at the windward stagnation can be used to represent the position of the boundary layer separation point (Figure 1). When the Reynolds number $10<$ $\mathrm{Re}_{D} \leq 1.5 \times 10^{5}$, the boundary layer separation point occurs in the range of $\varphi=80^{\circ} \sim 85^{\circ}$; when $\operatorname{Re}_{D}>1.5 \times 10^{5}$, the boundary layer is turned into a turbulent flow before separating, and the occurrence of separation is pushed back to the point at $\varphi=140^{\circ}$. Probe. The growth of boundary layer will inevitably lead to

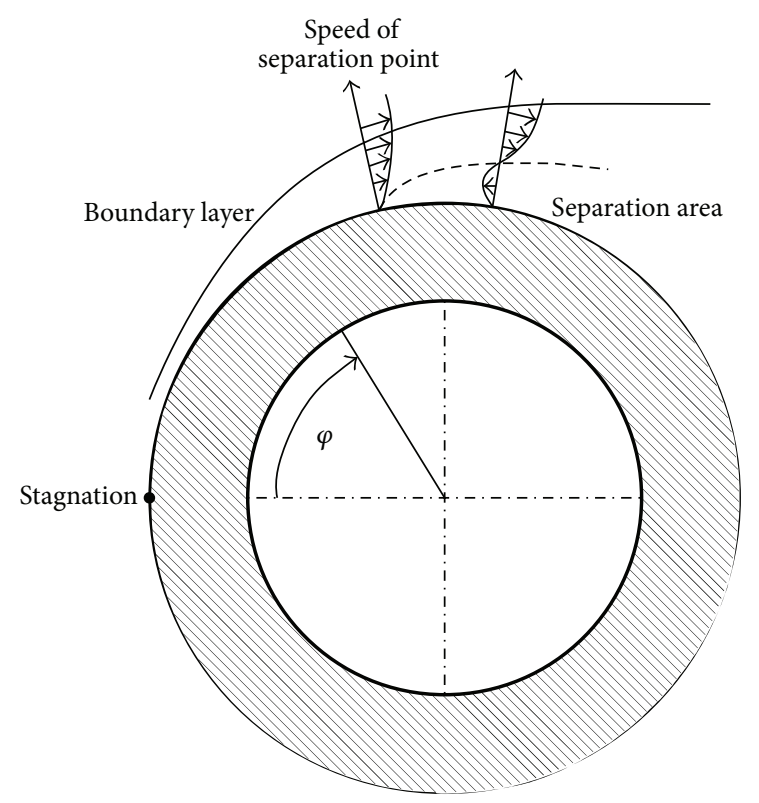

FIGURE 1: Separation of the boundary layer flow around a cylinder.

changes in the local heat transfer coefficient of a cylindrical probe. The heat transfer experiment for air flowing around the cylinder conducted by Giedt [15] revealed the distribution of the local $\mathrm{Nu}_{D}$ number along the wall (Figure 2). The curves show that the local heat transfer coefficient decreases with increasing angle in the range of $\varphi=80^{\circ} \sim 85^{\circ}$, because the laminar boundary layer is thickened continuously; the heat intensity is also weakened. At low Reynolds number, the rise of heat transfer coefficient reflects the separation of the boundary layer of fluid flowing around probe, because the disturbance of the fluid flowing off the probe strengthens the heat transfer. At low Reynolds number, the curve shows two distinct fluctuations in the region of fluid flowing off the probe, and at this time the separation of the boundary layer occurs at $\varphi=140^{\circ}$; in the range of $\varphi \approx 80^{\circ} \sim 140^{\circ}$, the increase of heat transfer coefficient is the result of the change from the boundary layer into a turbulent flow; after $\varphi>140^{\circ}$, the enhance of heat transfer results from the fluid flowing off the probe. From the three-dimensional perspective, as $\operatorname{Re}_{D}>$ 300 , the fluid flowing off the probe shows cycle distribution in the longitudinal direction of the cylinder, and the local heat transfer characteristics will become more complex.

If the configuration of thermal probe is a cylinder, the following conclusions can be drawn through the above analysis:

(a) The heat transfer coefficient of the probe increases with the increase of Reynolds number, and the heat transfer coefficient of the probe reflects the change in flow rate.

(b) The distribution of the local convective heat transfer coefficient on the surface of the probe in the circumferential direction fluctuates greatly.

(c) As the cut-off point to $\varphi \approx 80^{\circ}$, the local heat transfer coefficient of the thermal probe towards flow 


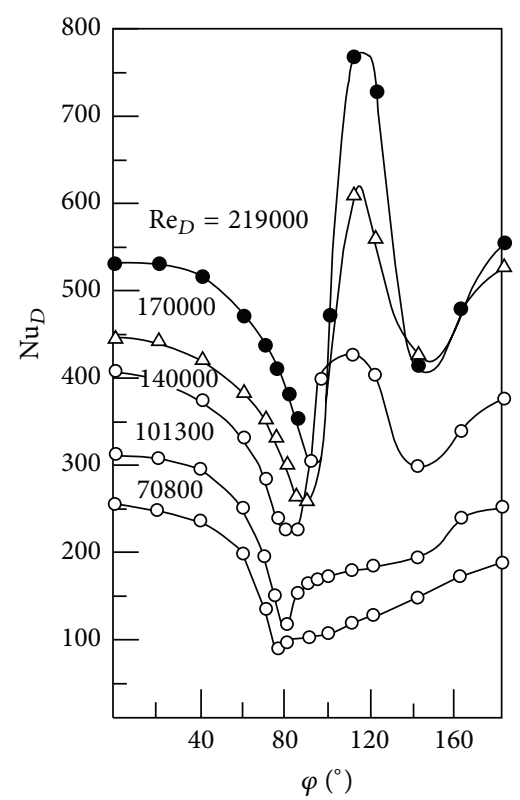

Figure 2: Giedt's local heat transfer coefficient of air flow around a cylinder.

surface performs good regularity, while it is irregular in the full range of Reynolds number in the opposite direction.

\section{The Numerical Simulation of Thermal Probe around Air}

Numerical simulations have been done to reveal the details of heat transfer characteristics of thermal probe in fluid.

4.1. Policy of Simulation. As a famous fluid simulation software, Fluent is chosen as the simulation tool and ICEM as the grid tool. Due to the asymmetry of the circular pipe with thermal probe, the simulation should be done under $3 \mathrm{D}$ model.

4.2. The Numerical Model and Grid. The thermal probe is comprised of two parts, the temperature detection part and velocity detection part, respectively. The diameter of probe defined to be $4 \mathrm{~mm}$. To avoid the influence of wake flow formed by temperature detection part, a heat insulation sub in velocity detection part is designed.

A whole view of simulation pipe, whose diameter is $50 \mathrm{~mm}$, is shown in Figure 3(c). The pipe wall is set to be thermally isolated. And the probe is settled in the middle of pipe. To insure the flow stableness, the pipe length is set to be 5 times as long as the pipe diameter.

The model grid generated by an unstructured grid method uses ICEM software as shown in Figure 3.

4.3. Colored Distribution of Probe Heat Transfer Coefficient. As illustrated in Figure 4, under the situation of air velocity $8.79 \mathrm{~m} / \mathrm{s}$, temperature $600 \mathrm{~K}$, and temperature difference between the velocity detection part and temperature detection part, the local heat transfer coefficient distribution corresponds well with the above analysis. The windward side of the probe is highly coefficient and more stable, and also a $3 \mathrm{D}$ distribution along the length can be observed.

\section{The Modification of Probe Design}

5.1. The Meaning of Local Heat Transfer Coefficient Distribution for Design of Thermal Probe. From the measurement point of view, it is expected that the heat transfer characteristics of the thermal probe are of stability and can change monotonously with the velocity of fluid. Then the probe should be designed to take full advantage of the heat transfer characteristics towards flow surface.

Known from the foregoing analysis and simulation results, making the local heat transfer structure of the thermal probe better can improve measurement performance of probe. The basic idea is that using hot-film probe and designing the layout configuration of hot-film on the probe makes the hot-film located on the most sensitive parts of the gas-solid heat transfer and reduces the transient measuring fluctuations caused by fluid trail (dynamic characteristics are not okay).

Based on this idea, the "partition" design of thermal probe can be taken into consideration, that is, taking the flow surface of probe as the heat exchange section and the tail part of probe as the adiabatic section (Figure 5), thus expanding the measuring range of thermal probe and effectively reducing fluctuations of the signal. The bolder idea is designing the probe to be ellipse or airfoil so that the fluid will not be separated in a wide range and the boundary layer region of the laminar flow will increase.

On the other hand, as the heat transfer area becomes small, the overall heat transfer coefficient of the probe will become small. In this way, in order to obtain a wide measuring range and stable signal, it needs to sacrifice part of the measuring system sensitivity. On balance, this partition design has more advantages.

5.2. The Modification Thermal Probe. Since the partition design method can improve the performance of the sensor, modification should be done.

First of all, the velocity detection part has a heat insulation sub covered by the wake flow of the temperature detection part. Mainly considering the strength and heat insulation characteristics, it is made of ceramics (as shown in Figure 3(a)).

And then, the partition design method was used inside the probe; the intersecting surface is shown in Figure 6. Considering the heat transfer and machining operation characteristics carefully, the velocity part was divided into two areas. One is for heat transfer and the other is for heat insulation, and the boundary angle is $160^{\circ}$. The heat transfer area is made of stainless steel and heat insulation area is also made of ceramics. The heating part is formed by a strut with platinum resistance wire on it, which is installed in the hole of heat transfer area. This design makes the probe choose the 


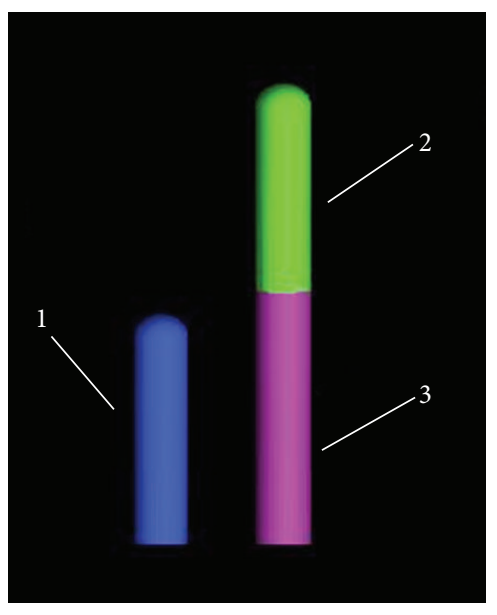

(a) Probe

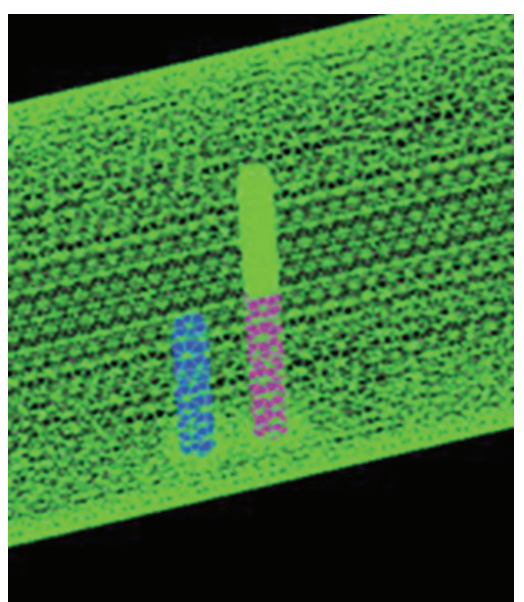

(b) Probe in pipe

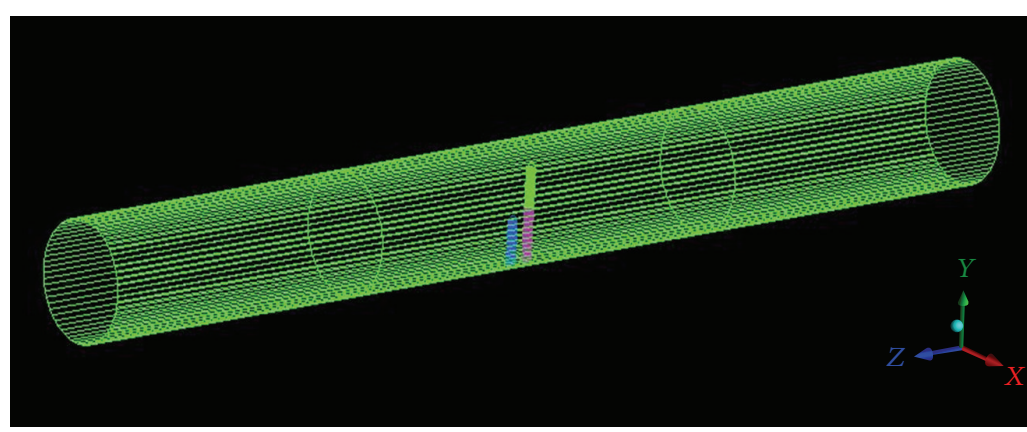

(c) The whole pipe

FIgURE 3: Model and grid of pipe with thermal probe. (1) Temperature detection part. (2) Heat transfer sub of velocity detection part. (3) Heat insulation sub of velocity detection part.

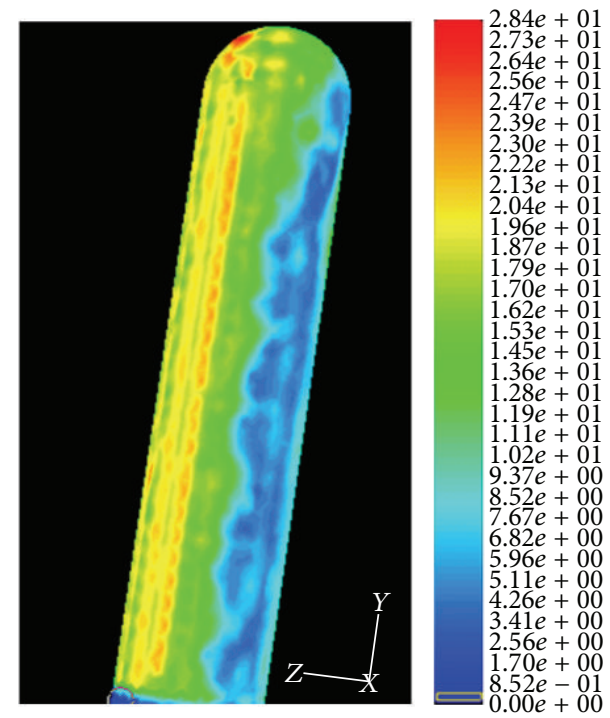

Figure 4: The colored heat transfer coefficient distribution.

stable and sensitive area of the probe cylinder. Consequently, the fluctuating output of measurement system is controlled, and then measuring range is extended.

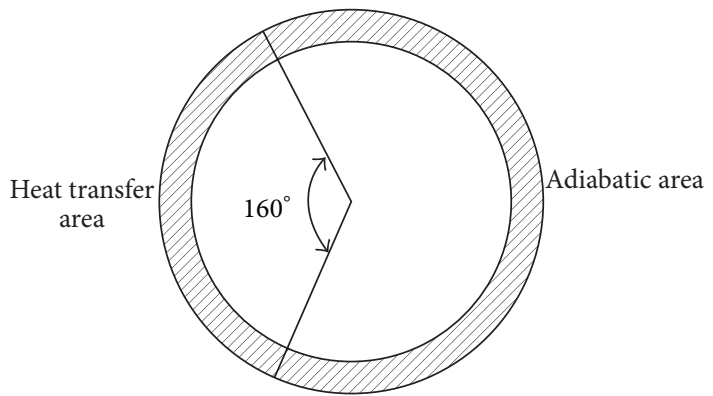

FIGURE 5: Heat transfer configuration design of probe at the cross section.

\section{The Experimental System and Results}

6.1. The Experimental System. The experimental system, which is based on the pipeline of diameter $50 \mathrm{~mm}$, has been designed and developed to facilitate the measurement of mass flow rate of the air in pipeline. Compressed air in pipeline is generated by a Roots blower and the speed is controlled by an invertor. According to the characteristics of the blower, the standard speeds in pipeline can be calculated and converted to the invertor frequency. The thermal probes (traditional 


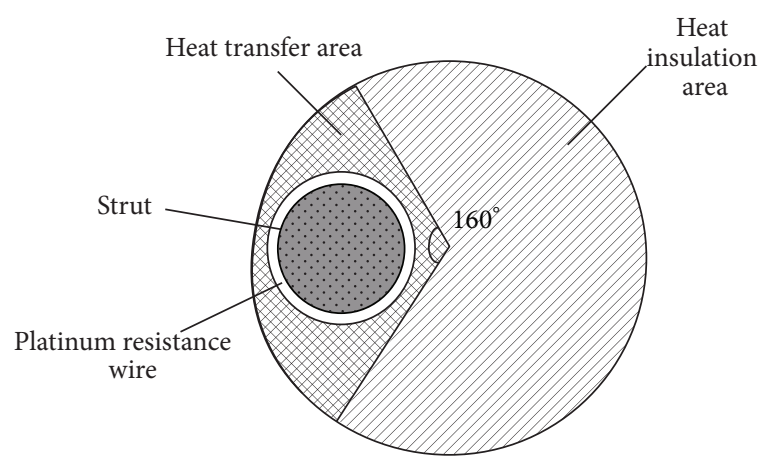

(a) The velocity part

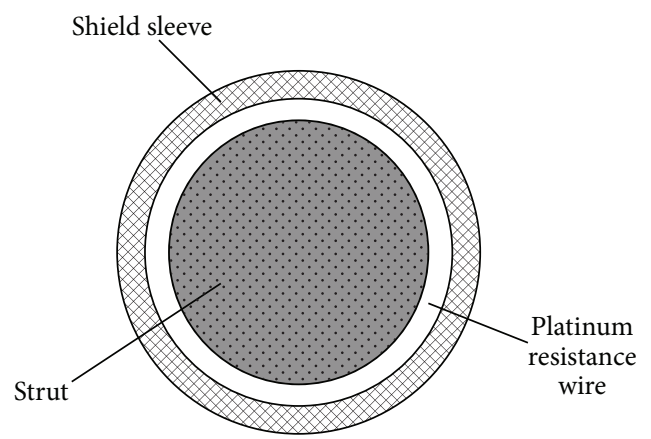

(b) The temperature part

FIGURE 6: Intersecting surface of the probe parts.

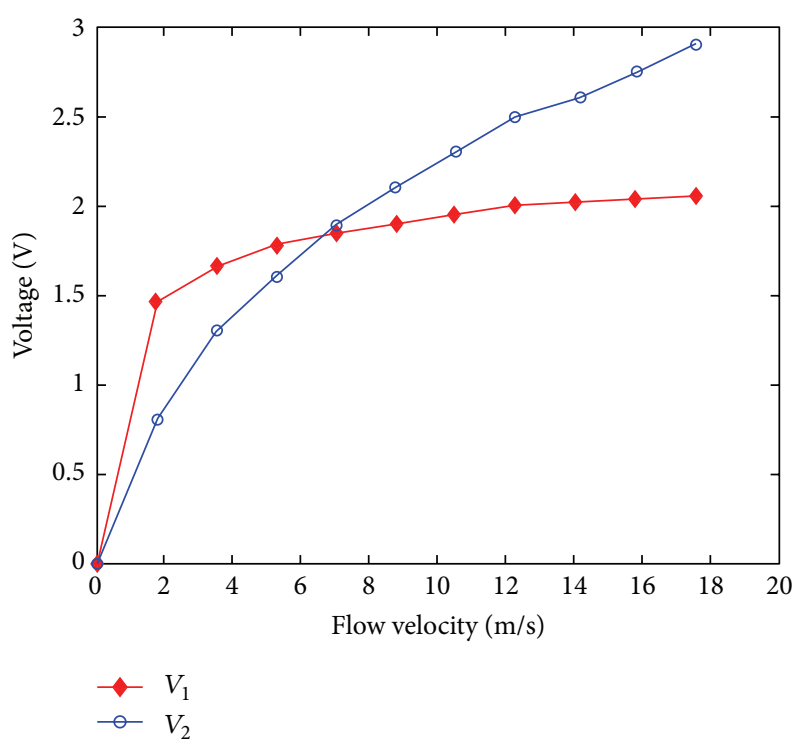

FIGURE 7: Curves of output voltages. $V_{1}$ : old type. $V_{2}$ : new type.

type probe and new modified probe) are inserted into the certain parts of the pipe to be tested and compared. A digital data acquisition device is used to deal with the outputs of the sensors and transmit the data to an industrial PC with USB interface. The industrial $\mathrm{PC}$ records the data to be analyzed.

6.2. The Experimental Results. The experiments are carried out while the temperature and speed of air vary to evaluate the performance of the measurement system.

While keeping the flow velocity to a certain value (about $5.3 \mathrm{~m} / \mathrm{s}$ ) and the temperature varying from $20^{\circ} \mathrm{C}$ to $60^{\circ} \mathrm{C}$, the output of the system is around $1.80 \mathrm{~V}$ with a little variation, as is shown in Table 1, which means that the probe has a good temperature compensation ability.

While changing the flow velocity at room temperature, it can be found that a typical nonlinear curve is fit to the theory of the thermal probe. But compared with the unmodified probe, the new curve is more flat and more linear (Table 2 and Figure 7).
TABLE 1: Result of experiment with conveying nothing.

\begin{tabular}{lcc}
\hline Flow velocity $(\mathrm{m} / \mathrm{s})$ & $V_{1}(\mathrm{~V})$ & $T\left({ }^{\circ} \mathrm{C}\right)$ \\
\hline 5.28 & 1.75 & 20.4 \\
5.30 & 1.73 & 30.0 \\
5.32 & 1.79 & 39.8 \\
5.27 & 1.78 & 50.3 \\
5.30 & 1.79 & 60.2 \\
\hline
\end{tabular}

TABLE 2: The flow velocity test with old probe and new probe $V_{1}$.

\begin{tabular}{lccc}
\hline $\begin{array}{l}\text { Temperature } \\
\left({ }^{\circ} \mathrm{C}\right)\end{array}$ & $\begin{array}{c}\text { Flow velocity } \\
(\mathrm{m} / \mathrm{s})\end{array}$ & $\begin{array}{c}V_{1}(\mathrm{~V}) \\
(\text { Old type })\end{array}$ & $\begin{array}{c}V_{2}(\mathrm{~V}) \\
\text { (New type) }\end{array}$ \\
\hline 21.0 & 0.00 & 0.01 & 0 \\
20.7 & 1.76 & 1.46 & 1.3 \\
20.4 & 3.51 & 1.66 & 1.55 \\
20.3 & 5.27 & 1.78 & 1.63 \\
20.2 & 7.03 & 1.85 & 1.78 \\
20.2 & 8.79 & 1.90 & 1.9 \\
20.2 & 10.54 & 1.95 & 2.1 \\
20.4 & 12.30 & 2.00 & 2.2 \\
20.5 & 14.06 & 2.02 & 2.6 \\
20.5 & 15.81 & 2.04 & 2.8 \\
20.8 & 17.57 & 2.05 & 3.7 \\
\hline
\end{tabular}

\section{Conclusions}

The probe used in a gas-solid mass flow-rate measurement system is designed and the analysis of the circuits is presented. As a key part of a data fusion method, the new modified probe changes the flow and heat transfer structure. The experiment in single phase flow illustrates the improvement of the performance of probe. The probe has potential to be of benefit to the future test of gas-solid two-phase flow.

\section{Conflict of Interests}

The authors declare that they have no conflict of interests. 


\section{References}

[1] Y. Zheng and Q. Liu, "Review of techniques for the mass flow rate measurement of pneumatically conveyed solids," Measurement, vol. 44, no. 4, pp. 589-604, 2011.

[2] T. Moriyama, S. Fujii, K. Abe, and M. Kobayashi, "Mass flowmeter using heat transfer for dense phase solid gas two phase flow," in Proceedings of Conference of the Fluid Control and Measurement, pp. 795-800, 1985.

[3] Y. Zheng, J. R. Pugh, D. McGlinchey, and R. O. Ansell, "Simulation and experimental study of gas-to-particle heat transfer for non-invasive mass flow measurement," Measurement, vol. 41, no. 4, pp. 446-454, 2008.

[4] Y. Zheng, D. McGlinchey, J. Pugh, and Y. Li, "Experimental investigation on heat transfer mechanisms of pneumatically conveyed solids' plugs as a means to mass flow rate measurement," Flow Measurement and Instrumentation, vol. 40, pp. 232237, 2014.

[5] L. Liu, Y. Wang, F. D. Zhou, and H. Qian, "Measurement of air flow and concentration of pulverized coal with two ellipseshaped thermal probes," Journal of Xian Jiaotong University, vol. 48, no. 1, pp. 23-26, 2008.

[6] Z. Yuan and Z. Lu, "A new method for measuring the solid flow rate in gas-solid two phase flow," Journal of Combustion Science and Technology, vol. 5, no. 1, pp. 52-56, 1999.

[7] H. Zhang and C. Li, "The experiments of the measuring method for gas-solid two-phase mass flow," Journal of Huazhong University of Science and Technology (Nature Science), vol. 30, pp. 75-77, 2002.

[8] C. Li, Y. Shao, and W. Li, "Measuring gas-solid two-phase mass flow based on thermal sensors fusion," Journal Huazhong University of Science and Technology, vol. 29, no. 8, pp. 50-52, 2001.

[9] H. Zhang, W. Zhang, and D. Ling, "Data fusion based thermal sensors for mass flow measurement in pneumatic conveying," Mathematical Problems in Engineering, vol. 2014, Article ID 314920, 8 pages, 2014.

[10] S. M. El-Behery, W. A. El-Askary, M. H. Hamed, and K. A. Ibrahim, "Hydrodynamic and thermal fields analysis in gassolid two-phase flow," International Journal of Heat and Fluid Flow, vol. 32, no. 3, pp. 740-754, 2011.

[11] L. Farbar and M. J. Morley, "Heat transfer to flowing gas-solids mixtures in a circular tube," Industrial \& Engineering Chemistry, vol. 49, no. 7, pp. 1143-1150, 1957.

[12] L. Farbar and C. A. Depew, "Heat transfer effects to gassolids mixtures using solid spherical particles of uniform size," Industrial \& Engineering Chemistry Fundamentals, vol. 2, no. 2, pp. 130-135, 1963.

[13] G. Jepson, A. Poll, and W. Smith, "Heat transfer from gas to wall in a gas-solids transport line," Transactions of the Institution of Chemical Engineers, vol. 41, pp. 207-211, 1963.

[14] M. Liu, C. Zhou, J. Xie, C. Lu, and Z. Wang, "Numerical investigation of performance of a fast gas-solid separator," Powder Technology, vol. 275, pp. 30-38, 2015.

[15] W. H. Giedt, "Investigation of variation of point unit-heattransfer coefficient around a cylinder normal to an air stream," Transactions of the ASME, vol. 71, pp. 375-381, 1949. 


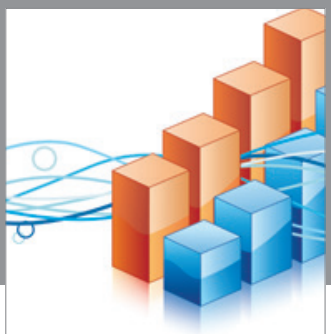

Advances in

Operations Research

vatem alat4

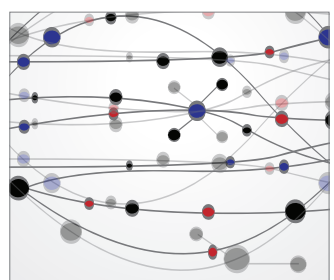

\section{The Scientific} World Journal
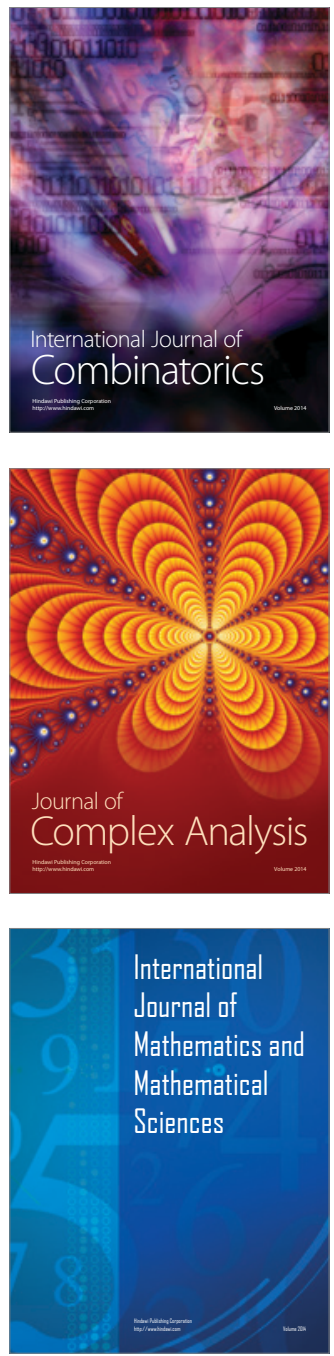
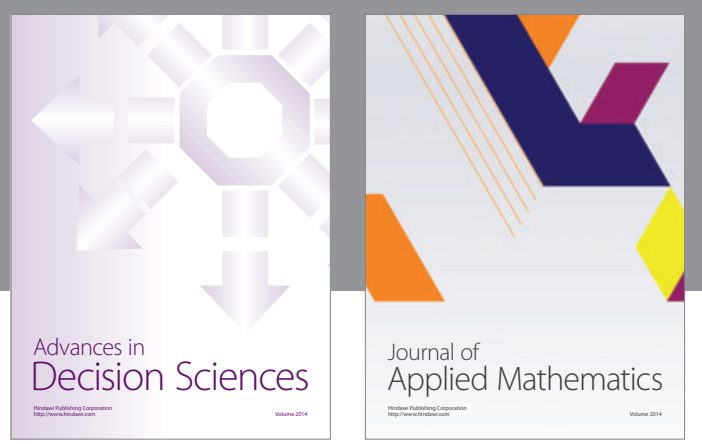

Algebra

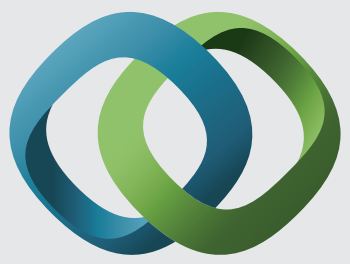

\section{Hindawi}

Submit your manuscripts at

http://www.hindawi.com
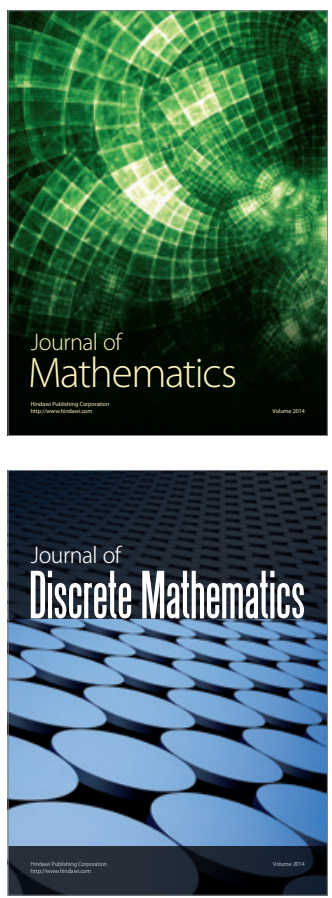

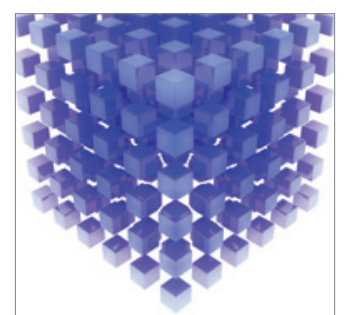

Mathematical Problems in Engineering
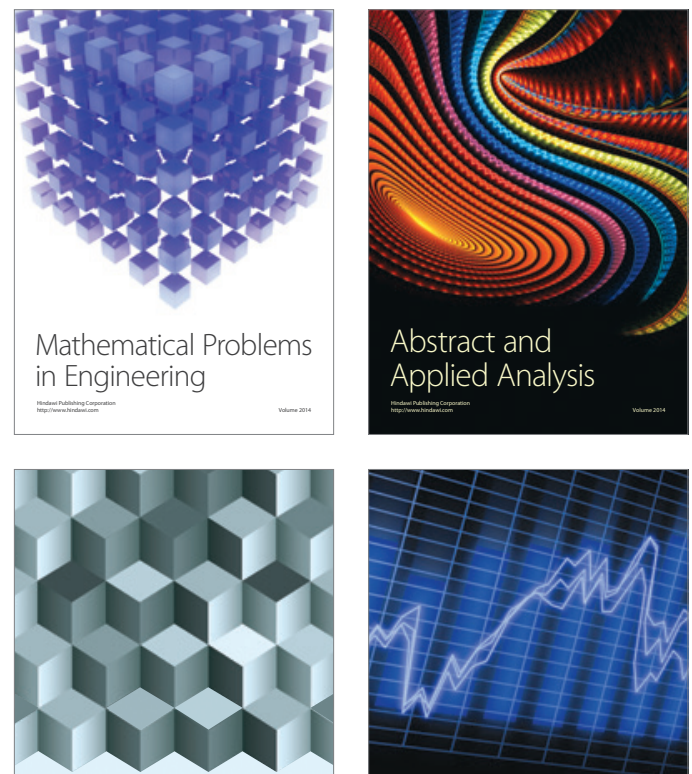

Journal of

Function Spaces

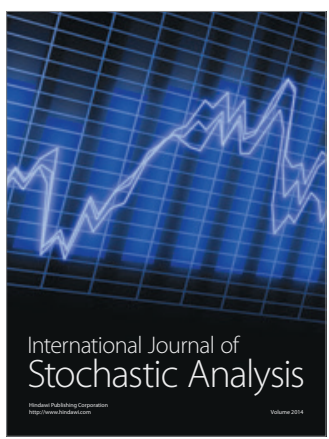

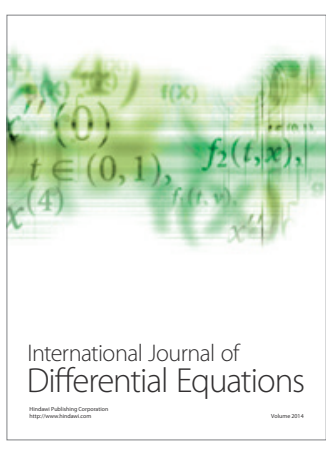
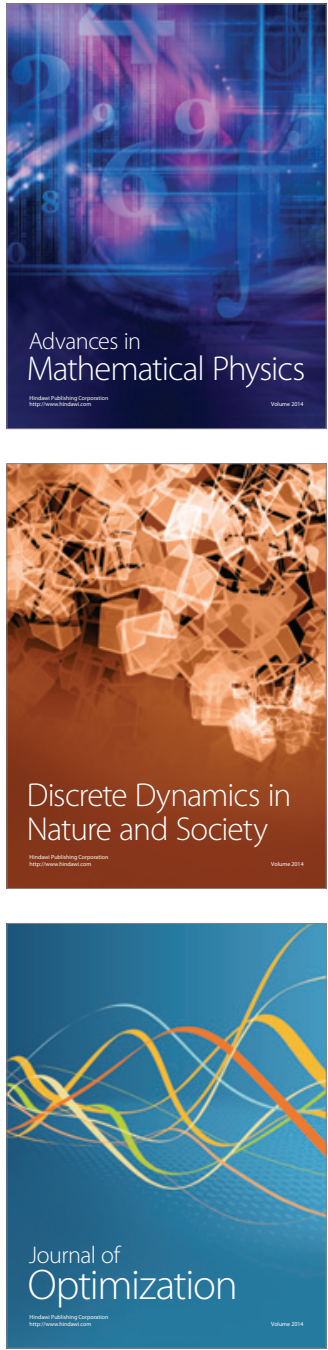